\title{
METODOLOGÍA PARA EL ANÁLISIS DE LAS TRANSFORMACIONES PAISAJÍSTICAS DE ÁREAS RURALES MEDITERRÁNEAS. EVOLUCIÓN, CAUSAS Y CONSECUENCIAS EN EL NORDESTE DE CATALUÑA*
}

\author{
Pere Serra ${ }^{1}$, David Saurí1 y Xavier Pons ${ }^{1,2}$ \\ ${ }^{1}$ Departamento de Geografía. Universitat Autònoma de Barcelona \\ ${ }^{2}$ Centre de Recerca Ecològica i Aplicacions Forestals (CREAF). Universitat Autònoma de Barcelona
}

\begin{abstract}
RESUMEN
El artículo presenta una metodología aplicable al análisis de las dinámicas paisajísticas de las áreas rurales mediterráneas a través del uso conjunto de cuatro herramientas: historia, teledetección con imágenes de satélite, regresión multivariante e índices paisajísticos. El primer proceso consiste en el análisis histórico cuyo objetivo es comprender como la acción humana ha transformado el paisaje a través de los siglos. El segundo es el uso de la teledetección y de los sistemas de información geográfica para la obtención de los mapas de cubiertas y usos del suelo de las últimas décadas. A causa de los sensores usados (Multispectral Scanner (MSS) y Thematic Mapper (TM)) se han diferenciado dos subperiodos: 1977-1993, analizado a través de imágenes MSS, y 1991-1997, a través de imágenes TM. En el tercer paso, se analizan las fuerzas inductoras de los cambios a través de la aplicación de la regresión lineal y de la regresión logística multivariante. Finalmente, se cuantifica la evolución paisajística a través de diversos índices propuestos por la Ecología del Paisaje.
\end{abstract}

Palabras clave: paisaje mediterráneo, cubiertas y usos del suelo, teledetección y sistemas de información geográfica, regresión lineal y logística multivariante.

\section{ABSTRACT}

The paper presents a methodology for analysing the landscape dynamics of Mediterranean rural areas using four tools: historical accounts, satellite remote sensing, multivariate regression and landscape indices. The first step involves in historical analysis to

\footnotetext{
Parte de los resultados fueron presentados en el XVIII Congreso de la Asociación de Geógrafos Españoles bajo el título: «Análisis de las dinámicas recientes (1977-1997) de los paisajes agrarios mediterráneos. El caso de l'Alt Empordà (Nordeste de Catalunya)», realizado en la Universitat Autònoma de Barcelona del 24 al 27 de septiembre de 2003.
} 
understand how human action has transformed the landscape. The second is the use of remote sensing and geographical information systems to obtain land cover and land use maps from the last decades. Due to the sensors used (Multispectral Scanner (MSS) and Thematic Mapper (TM)) two periods have been differentiated: 1977-1993 analysed with MSS images and 1991-1997 with TM images. In the third step driving forces of land cover and land use changes have been analysed by means of multivariate linear regression and logistic regression. Finally, the landscape evolution has been quantified through diverse indices extracted from Landscape Ecology.

Key words: Mediterranean landscape, land cover and land use, remote sensing and geographical information systems, multivariate linear and logistic regression.

\section{Introducción}

En los últimos años, las herramientas geográficas de análisis territorial mediante cubiertas y usos del suelo (CUS) han evolucionado considerablemente. Así, la existencia de datos censales más detallados y de cartografía más fiable posibilita el análisis de la evolución territorial y paisajística con un grado de precisión anteriormente inimaginable. En consecuencia, uno de los principales retos actuales del análisis geográfico es la integración de herramientas cartográficas y de datos georeferenciados, mientras que en el caso de la modelización de los cambios en las CUS destaca el enorme interés por integrar tanto los factores biofísicos como los socioeconómicos que los inducen (Liverman et al., 1998).

El objetivo central del artículo radica en la aplicación de una metodología para el análisis de las dinámicas paisajísticas en general y de las agrarias en particular, empleando diversas herramientas y datos. En su transcurso se expondrán los problemas detectados así como sus posibles soluciones. La metodología se basa en cuatro apartados: el primero comprende el análisis histórico de los cambios en las CUS. El análisis histórico puede desarrollarse básicamente a través de dos fuentes de información: por un lado las fuentes documentales (escritas, gráficas, etc.) y, por otro lado, las paleobotánicas (que incluyen la palinología, la antracología, la dendrología, etc.; Lowe y Walter, 1997) que permiten un análisis más retrospectivo en el tiempo.

Las fuentes principales para la obtención de mapas de CUS así como de sus cambios son el trabajo de campo y la teledetección. El trabajo de campo ha experimentado un extraordinario avance con la técnica del Global Positionning System (GPS) mientras que la teledetección (tradicionalmente la fotografía aérea) ha mejorado significativamente con la aportación de las imágenes de satélite. La combinación de ambas fuentes a través de un sistema de información geográfica (SIG) permite un análisis más o menos detallado de la evolución de las CUS, en función, entre otros factores, del sensor utilizado. El periodo analizado comprende de 1977 a 1997 ya que se han dispuesto de las oportunas imágenes de satélite; por los motivos que se detallarán más adelante, en el análisis se han diferenciando dos subperiodos, de 1977 a 1993 y de 1991 a 1997.

El tercer apartado comprende el análisis de las fuerzas inductoras (población etc.; Walter, 1977; Díaz, 1986)) de las transformaciones sintetizadas anteriormente a través de la integración de los mapas obtenidos y de los datos socioeconómicos y biofísicos georeferenciados. La propuesta metodológica se basa en la aplicación de la regresión con el objetivo de predecir las variables dependientes (las CUS obtenidas con la teledetección) a través de las variables independientes (los datos socioeconómicos y biofísicos). Existen diversos ejemplos de aplicación de la estadística para el análisis de las fuerzas inductoras de los cam- 
bios en las CUS. Así, por ejemplo, Koning et al. (1998) emplean la regresión lineal multivariante al análisis de las CUS del Ecuador según los límites parroquiales, mientras que Wood y Skole (1998) la aplican en diversos municipios del Amazonas. Sin embargo, los resultados muestran, como los mismos autores reconocen, una capacidad predictiva reducida (presentan unos coeficientes de determinación $\left(\mathrm{R}^{2}\right)$ bastante bajos), aspecto que se intenta mejorar con la metodología propuesta.

En el último apartado se analizan las consecuencias socioambientales de los cambios, esencialmente en relación al paisaje. Para ello se propone aplicar diversos índices empleados desde la Ecología del Paisaje con el objetivo de cuantificar, en cada uno de los subperiodos y para cada una de las CUS, su evolución, determinando si están afectadas por procesos de fragmentación o de homogeneización.

\section{Metodología}

\section{1. Área de estudio y análisis histórico}

El análisis histórico se ha realizado a través de distintas fuentes bibliográficas que permiten monitorizar las modificaciones más importantes realizadas por la acción humana desde la Edad Media hasta la actualidad.

El área de estudio abarca veintiún municipios situados al noreste de Catalunya y pertenecientes a la comarca del Alto Ampurdán (43 516 ha, en total) (Mapas 1 y 2). Morfológicamente incluye tres subzonas: la primera, la zona llana, abarca los municipios situados entre los 0 y $100 \mathrm{~m}$ de altitud y con una larga tradición en cultivos herbáceos. La segunda la configura la zona de transición, situada entre los 100 y $400 \mathrm{~m}$ de altitud, donde predominan los cultivos permanentes, especialmente vides y olivos, y los matorrales. Finalmente, la tercera la forma la zona de montaña, a partir de los $400 \mathrm{~m}$ de altitud, con predominio del encinar y de los caducifolios (hayas, robles, etc.).

En la Edad Media, la población de la zona llana agrícola se localizaba en los pequeños montículos que emergían de la gran marisma que formaron los sedimentos de los dos prin-

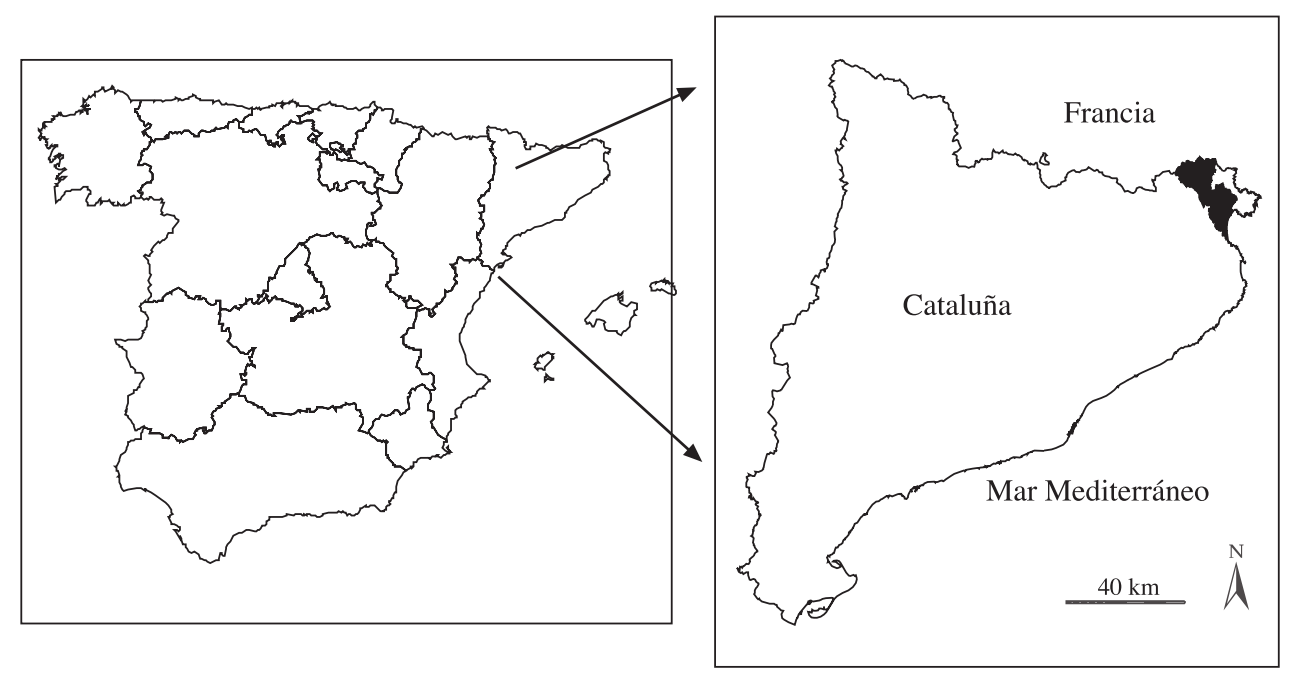

MAPA 1: Área de estudio en negro. 


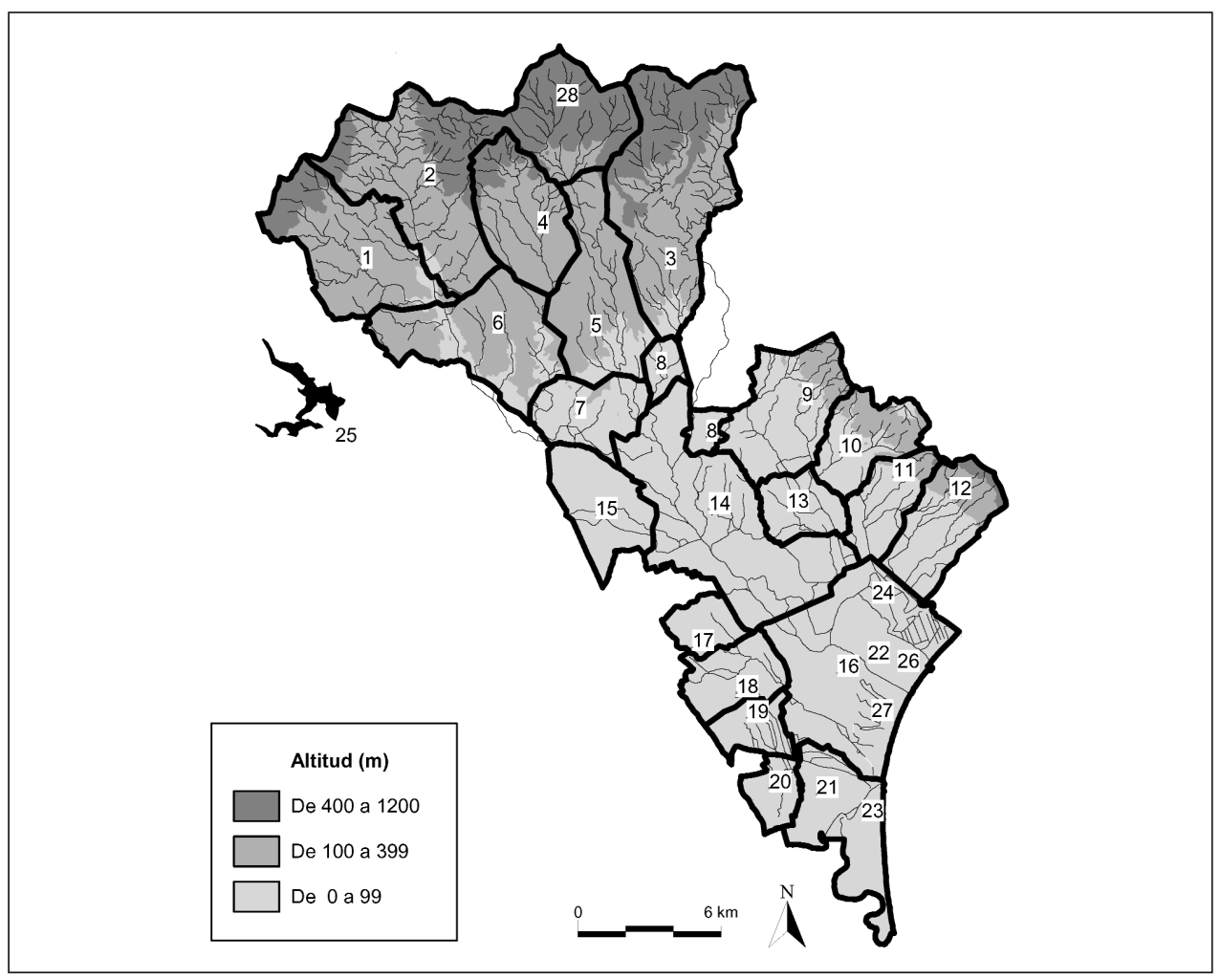

\begin{tabular}{|l|l|}
\hline Municipios de montaña & 14. Peralada \\
\hline 1. Agullana & 15. Cabanes \\
\hline 2. La Jonquera & 16. Castelló d'Empúries \\
\hline 3. Espolla & 17. Vila-Sacra \\
\hline Municipios de transición & 18. Fortià \\
\hline 4. Cantallops & 19. Riumors \\
\hline 5. Sant Climent Sescebes & 20. Vilamacolum \\
\hline 6. Capmany & 21. Sant Pere Pescador \\
\hline 7. Masarac & Otros topónimos \\
\hline 8. Mollet de Peralada & 22. Río Muga \\
\hline 9. Garriguella & 23. Río Fluvià \\
\hline 10. Vilajuïga & 24. Antigua laguna de Castelló d'Empúries \\
\hline 11. Pau & 25. Pantano de Boadella \\
\hline 12. Palau-Saverdera & 26. Macrourbanización Empúriabrava \\
\hline Municipios de llanura & 27. Parque Aiguamolls del Ampurdán \\
\hline 13. Pedret i Marzà & \\
\hline
\end{tabular}

MAPA 2. Área de estudio detallada. 
cipales ríos que desembocan en el área de estudio, el Fluvià y la Muga. En la zona de transición, los asentamientos humanos se emplazaron al pie de la Sierra de Rodes, mientras que alrededor de los cursos fluviales se desarrollaron los núcleos de los municipios forestales (Compte, 1963-64).

En la zona de transición, las primeras roturas para el cultivo de la vid y del olivar se produjeron a partir del siglo XIII en detrimiento del encinar (Armengol, 1978). Por su parte, en la zona llana, durante los siglos XIV y XV, tuvo lugar la primera desecación parcial de la laguna de Castelló d'Empúries. Ya en el s. XVIII, la agricultura tradicional, basada en la rotación de los cereales con el barbecho, se transformó con la aparición de nuevas técnicas agrícolas, provenientes del sur de Francia, y la introducción de nuevos cultivos, básicamente el maíz, los forrajes de tipo rotativo y la patata. Este cambio fue impulsado por el crecimiento demográfico y por el incremento de la superficie cultivada, gracias a la nueva desecación de lagos y lagunas y al desvío de la desembocadura de los ríos Fluvià y Muga.

Durante el s. XIX se produjo una nueva expansión de la superficie cultivada, relacionada con la desamortización, a través de la desecación de más lagunas, empleando minas y bombas de agua, y del incremento de la mecanización. En ese periodo se instauró la trilogía clásica de los cereales de invierno, el maíz y la alfalfa. En la zona de montaña, la actividad principal estaba ligada a la explotación del corcho que tuvo su etapa álgida en ese siglo. En la zona de transición, la aparición de la filoxera comportó la desaparición provisional de la vid, que se convirtió en permanente en las zonas más elevadas debido al difícil acceso y a los suelos más pobres.

A partir de 1966, tuvo lugar una importante transformación en el sector agrícola debido a la construcción del pantano de Boadella y al inicio del proyecto del Plan de Regadío del Muga. El sector agrario se caracterizaba en esos años por la reducida superficie del regadío (2 380 ha, un 5.5\% del total territorial), por la fragmentación parcelaria (el 64.5\% de la parcelas ocupaban menos de 1 ha) y por la importancia de la aparcería (casi un $25 \%$ de la tierra tenía ese régimen de tenencia) (INE, 1964).

La aparición del turismo de masas y de segunda residencia tuvo un fuerte impacto en los municipios costeros, principalmente a partir de mediados de 1960 con el inicio de la macrourbanización Empúriabrava (que actualmente ocupa más de 500 ha) que comportó la privatización y desaparición de marismas y cultivos, promovida por la iniciativa privada y con el visto bueno del ayuntamiento, en una etapa predemocrática que estimuló la especulación en los años venideros. Fruto de este afán constructivo, la presión popular pudo detener nuevas iniciativas constructoras y crear el Parque de los Aiguamolls (marismas) del Ampurdán, que protege los restos de las antiguamente extensas marismas ampurdanesas.

\subsection{Teledetección y cambios en las cubiertas y usos del suelo}

Existen multitud de satélites de observación de la Tierra desde los de baja resolución espacial como el Advanced Very High Resolution Radiometer (AVHRR del satélite NOAA) con un píxel de $1.1 \mathrm{~km}$ hasta los de alta resolución como el Ikonos con un píxel entre 1 y 4 m. El primer satélite civil de observación terrestre fue el Earth Resources Technology Satellite (ERTS), lanzado el 23 de julio de 1972 y considerado el primero de la serie Landsat. Desde entonces se han lanzado seis versiones más, siendo la más reciente la del Landsat-7 en órbita desde abril de 1999.

Las imágenes usadas en este trabajo han sido las correspondientes al sensor Multisprectal Scanner (MSS) del satélite Landsat-2 y al sensor Thematic Mapper (TM) del satélite Landsat-5. Las primeras tenían una medida de píxel nominal de $57 \mathrm{~m} * 79 \mathrm{~m}$ siendo remuestreadas a $60 \mathrm{~m}$ x $60 \mathrm{~m}$ mientras que las TM tenían píxeles de 30m x 30m. La mayor riqueza 
espectral, o sea, la captación de diferentes longitudes de onda (las MSS tenían cuatro canales de 0.5 a $1.1 \mu \mathrm{m}$, mientras que las TM siete, tres visibles de 0.45 a $0.69 \mu \mathrm{m}$, tres infrarojos de 0.76 a $2.35 \mu \mathrm{m}$ y un canal térmico de $10.4 \mathrm{a} 12.5 \mu \mathrm{m}$ ) y temporal (por ejemplo en el caso de Landsat la captación de las imágenes se produce a la misma hora cada 16 días) de las imágenes de satélite respecto a las fotografías aéreas permite analizar, en muchos casos, las CUS y sus cambios con una mayor precisión temática. Así, como en el caso del área de estudio presentada donde predominan los cultivos y las cubiertas forestales, a través de las técnicas propias de la teledetección satelitaria se pueden discriminar, con una metodología adecuada, cultivos y especies forestales específicos como el maíz, los cereales de invierno, hayedos y robles, etc.

Debido a que el análisis se realizó a través de imágenes de satélite, el primer mapa de CUS se estableció para 1977 y el último en 1997. Como consecuencia de las mejoras introducidas en los sensores de la serie Landsat (mejor resolución espacial, etc.), se estableció dos subperiodos: de 1977 a 1993 empleando imágenes MSS y de 1991 a 1997 con TM. Con ello se evitó comparar resultados obtenidos con herramientas distintas y la posibilidad de obtener resultados ficticios (Serra et al.2003b). En cada subperiodo se empleó más de una imagen para cubrir el periodo vegetativo de primavera y verano, en otras palabras, para cubrir la evolución fenológica de la vegetación. Finalmente, las imágenes empleadas fueron tres Landsat MSS para el mapa de CUS de 1977 (17 de julio de 1977, 2 de junio de 1978 y 18 de septiembre de 1978), dos Landsat MSS para el mapa de CUS de 1993 (28 de junio de 1993 y 31 de agosto de 1993), 2 Landsat TM para el mapa de CUS de 1991 (22 de mayo de 1991 y 19 de julio de 1992) y tres imágenes de Lansdsat TM para el mapa de 1997 (20 de junio de 1996, 9 de julio de 1997 y 23 de agosto de 1996). La situación ideal habría sido disponer de imágenes de diferentes meses del mismo año, sobretodo para evitar cambios agrícola interanuales, pero no fue posible debido a la cobertura nubosa.

La metodología empleada para la obtención de las CUS se basa en tres etapas: la primera comprende la corrección geométrica de las imágenes a través del método de Palà y Pons (1995). El objetivo reside en la eliminación de las distorsiones producidas por el movimiento del satélite, por la rotación y curvatura terrestre, etc., y en el coregistro de todas las imágenes a unas coordenadas comunes. Todos los Root Mean Squared ${ }^{1}$ (RMS) obtenidos fueron inferiores a un píxel (de 60 y $30 \mathrm{~m}$, respectivamente). La segunda corresponde a la corrección radiométrica que se aplica con el objetivo de obtener unos valores radiométricos cercanos a los obtenidos con una recepción perfecta considerando la iluminación que recibe cada píxel en función de la posición solar, etc. (Pons y Solé-Sugrañes, 1994).

Las CUS objetivo para las clasificaciones con MSS (1977 y 1993) fueron el maíz de regadío, otros herbáceos de regadío (alfalfa, sorgo, etc.), los cereales de invierno (trigo, cebada y centeno) y el barbecho, los frutales, los olivos y las vides, los matorrales, los caducifolios, los esclerófilos, los prados y pastizales y la superficie urbana. Para las clasificaciones con TM (1991 y 1997) se emplearon las mismas CUS más el arroz y el girasol, debido a su inexistencia a mediados de los 1970s.

Una de las ventajas de trabajar con imágenes de satélite comparado con fotografías aéreas no digitales es que los mapas de CUS pueden provenir de clasificaciones automáticas. Para su obtención se aplicó un clasificador mixto (Serra et al., 2003a) combinando una clasificación no supervisada realizada a través del algoritmo ISODATA (Interactive Self Organizing Data Analisis) (Chuvieco, 2002) y áreas de entrenamiento típicas de los sistemas supervisados, obteniéndose un porcentaje de acierto superior al $85 \%$ en los cuatro

1 Indicador de la calidad de la corrección geométrica a través de la raíz cuadrada de las desviaciones entre los valores observados y los estimados (Chuvieco, 2002). 
mapas. Para la cuantificación de los cambios en las CUS se usó el método de postclasificación, que consiste en sobreponer dos mapas y obtener la matriz de cambios.

Los resultados mostraron, en la zona llana, una intensificación de los cultivos herbáceos a costa de pastos y pastizales (principalmente entre 1977 y 1993 ya que este proceso se ralentizó entre 1991 y 1997), la intensificación de los herbáceos de regadío (1977-1993), la aparición generalizada del girasol en detrimento de los cereales de invierno y la concentración de frutales en el municipio de Sant Pere Pescador en detrimiento de los cultivos herbáceos (entre 1991 y 1997) (mapas 3-6).

En la zona de transición los cambios más significativos fueron el abandono o transformación de vides y olivos (significativamente entre 1977 y 1993 y afectando las cultivadas en pendientes más pronunciadas) (mapas 7 y 8) y la no regeneración forestal de los matorrales (mapa 9). Finalmente, en la zona de montaña hubo un incremento de los matorrales en detrimento de la superficie forestal (entre 1977 y 1993 debido a los incendios forestales de 1986) (mapa 10), un importante descenso de vides y olivos al sur del municipio de Espolla (mapa 7), mientras que entre 1991 y 1997 se produjo el proceso contrario (regeneración forestal) (mapa 11) y un estancamiento en el retroceso de vides y olivos.

\subsection{Fuerzas inductoras de los cambios de las CUS}

\subsubsection{Regresión lineal multivariante}

El tercer paso consiste en la aplicación del análisis estadístico con el objetivo de establecer las fuerzas inductoras de las transformaciones anteriormente descritas. A continuación, se detallan dos posibles métodos: el primero es la regresión lineal multivariante a escala municipal y la segunda es la regresión logística multivariante a escala de píxel.

El primer paso para la aplicación de la regresión lineal multivariante a escala municipal fue la compilación de las variables socioeconómicas y biofísicas que conformarían las variables independientes del modelo (tabla 1).

\begin{tabular}{|l|l|}
\hline Variables socioeconómicas & Precio máximo del suelo de secano y de regadío \\
\hline Superficie municipal & Hectáreas de zonas protegidas \\
\hline Número de habitantes, densidad de población & Hectáreas subsidiadas PAC en régimen general, \\
\hline & simplificado, en el maíz y en el girasol \\
\hline Viviendas principales y viviendas secundarias & Variables biofísicas \\
\hline Plazas de camping y plazas hoteleras & Altitud en $\mathrm{m}$ \\
\hline Ocupados en agricultura, industria, etc. & Pendiente en ${ }^{\circ} \mathrm{C}$ \\
\hline Superficie agraria útil (SAU) en propiedad, etc. & Radiación solar en $\mathrm{kJ} / \mathrm{m}^{2}$ \\
\hline Número de explotaciones agrarias según tamaño & Precipitación en $\mathrm{mm}$ \\
\hline Número de parcelas por superficies & Litología \\
\hline Titulares de las explotaciones por edades & Temperatura media anual de las mínimas en ${ }^{\circ} \mathrm{C}$ \\
\hline Número de empresarios con ocupación principal agraria & Temperatura media anual en ${ }^{\circ} \mathrm{C}$ \\
\hline Ganadería: bovinos, etc. & Temperatura media anual de las máximas en ${ }^{\circ} \mathrm{C}$ \\
\hline Hectáreas afectadas por el Plan de regadío del Muga & Hectáreas quemadas en incendios forestales \\
\hline
\end{tabular}

TABLA 1: variables socioeconómicas y biofísicas introducidas en el análisis estadístico como independientes. 
Intensificación agrícola (1977-1993):

de prados y pastizales a cultivos herbáceos

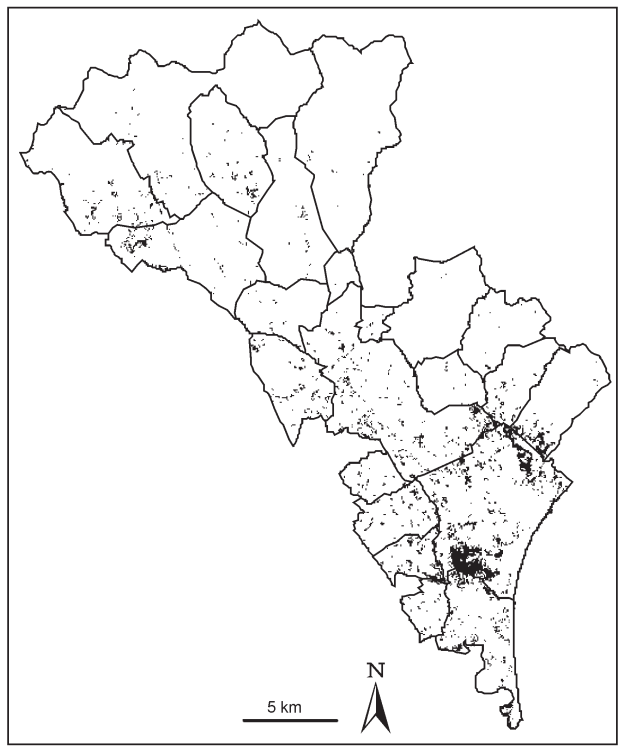

MAPA 3.

De cereales de invierno a girasol (1991-1997)

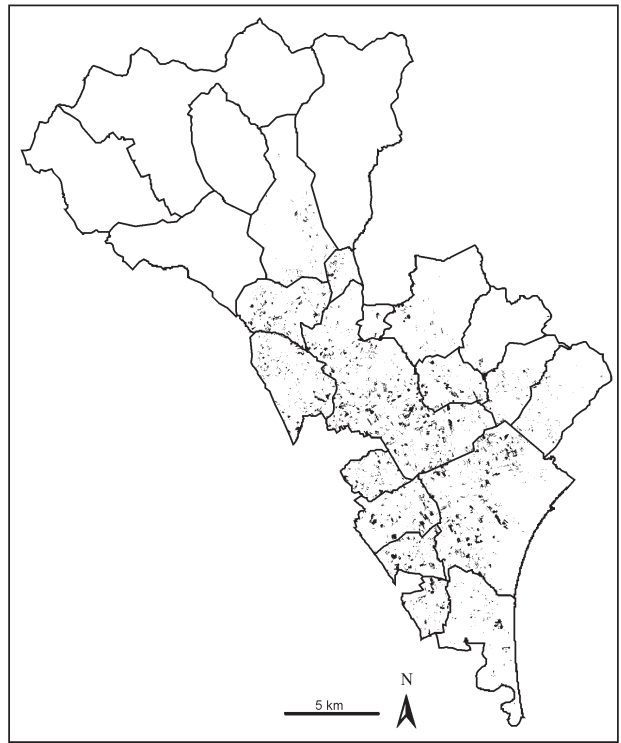

MAPA 5.
Intensificación herbáceos regadío (1977-1993): de cereales de invierno a herbáceos de regadío

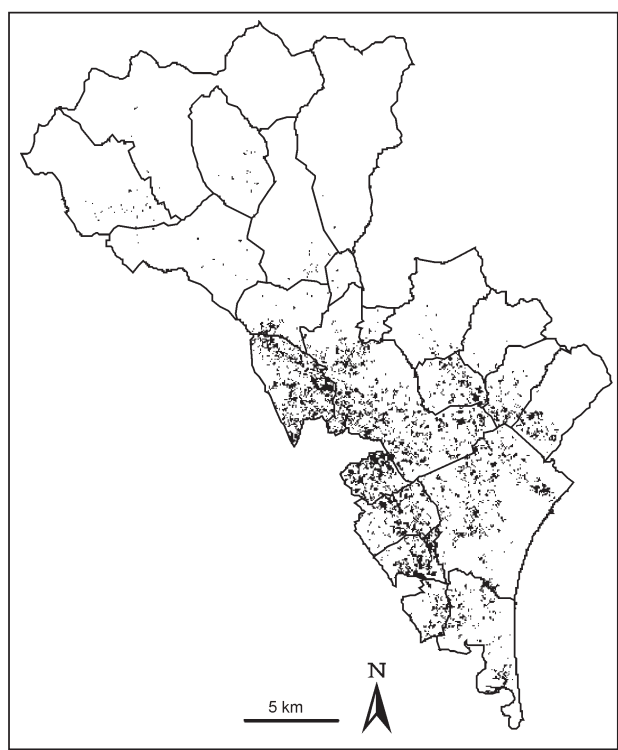

MAPA 4.

De herbáceos a frutales (1991-1997)

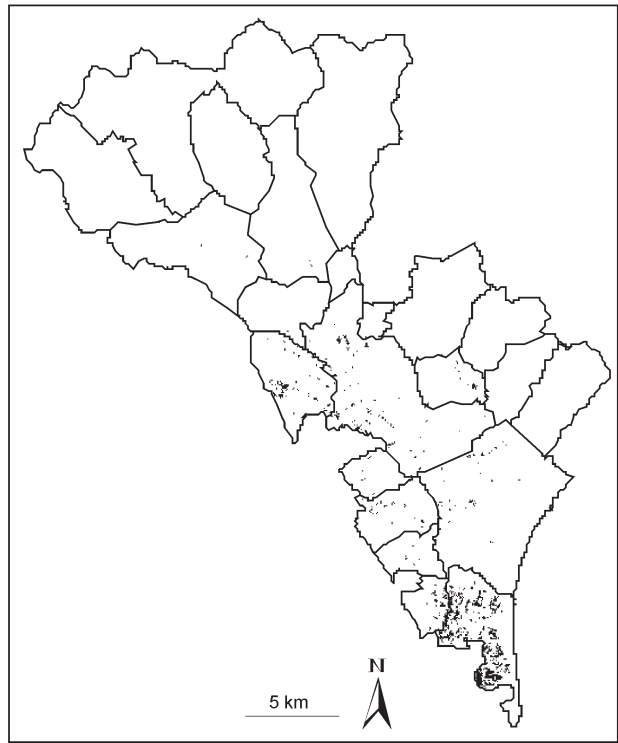

MAPA 6. 
Abandono de vides y olivos (1977-1993): a matorrales

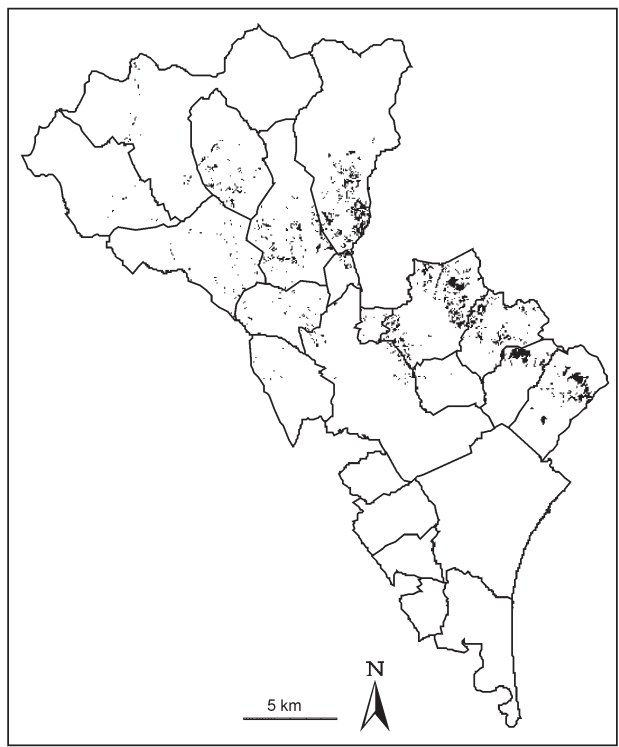

MAPA 7.

No regeneración forestal (1977-1993): de matorrales a matorrales

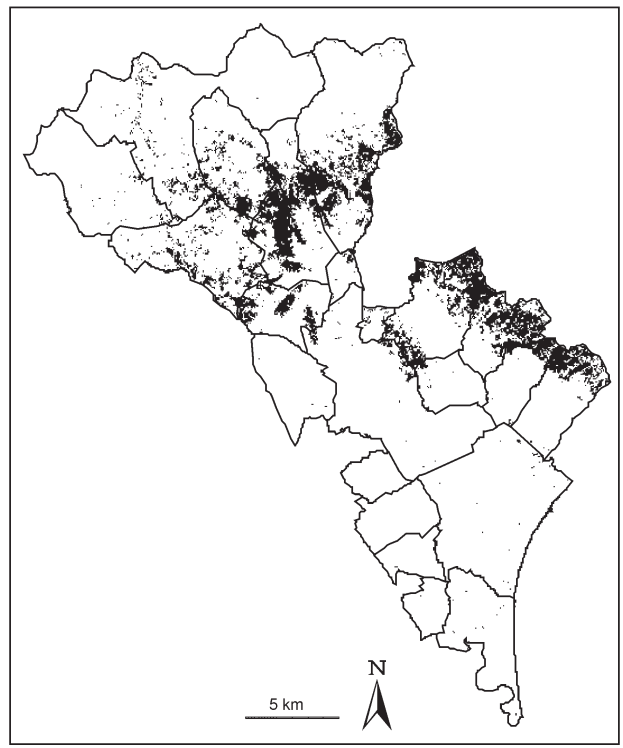

MAPA 9.
Transformación de vides a herbáceos (1977-1993)

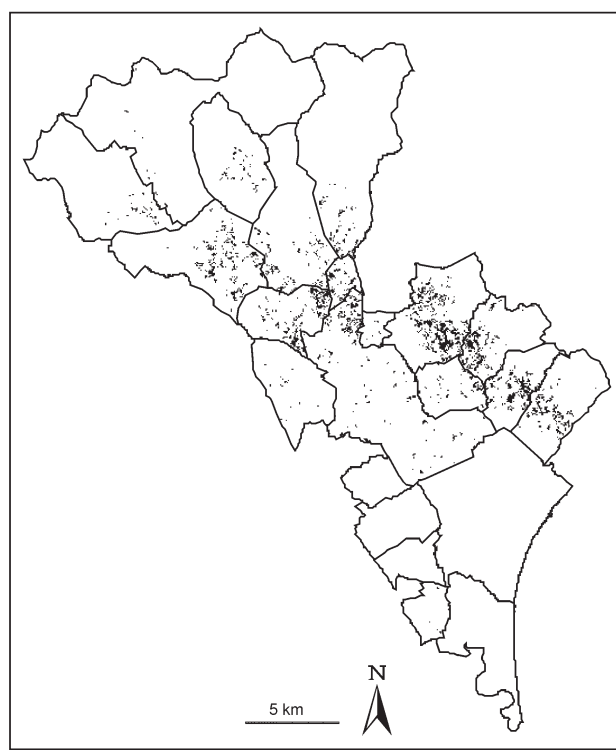

MAPA 8.

Incendios forestales 1977-1993: de esclerófilos a matorrales

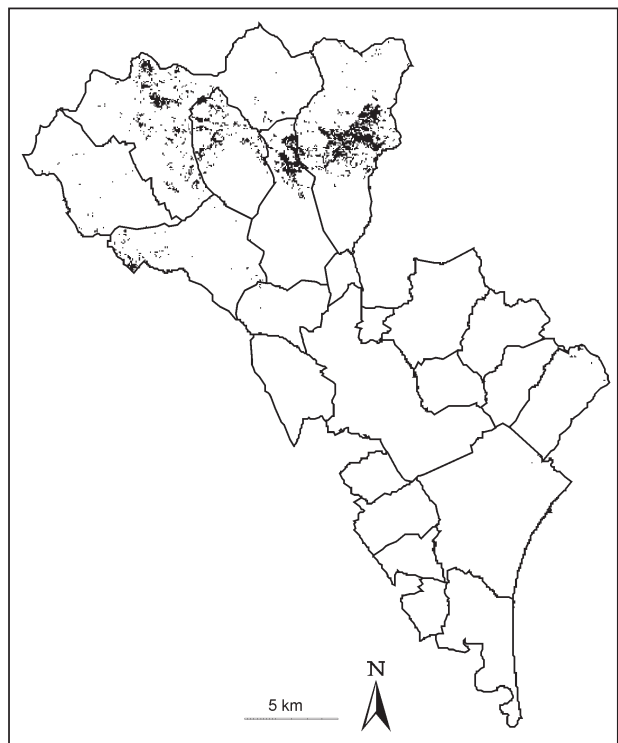

MAPA 10. 
Regeneración incendios forestales (1991-1997): de matorrales a superficie forestal

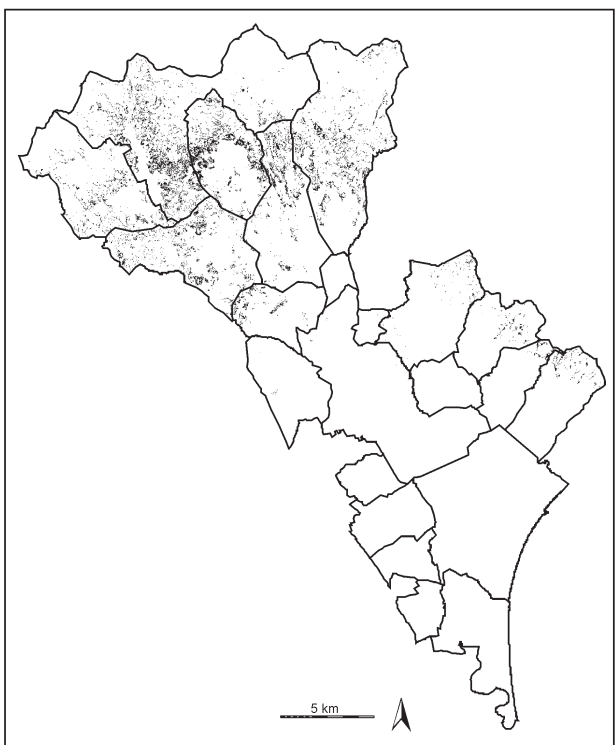

MAPA 11.

La inclusión de las variables socioeconómicas no comportó problemas ya que todas ellas estaban agregadas, en las diferentes fuentes bibliográficas (censos agrarios, etc.), por municipios. En relación a las variables biofísicas, las fuentes fueron los mapas digitales de precipitación, radiación solar, etc. del Atlas Climático Digital de Cataluña (http://magno.uab.es/atles-climatic/index_es.htm y Ninyerola et al., 1999) con una medida de píxel de $180 \mathrm{~m}$ x 180m, un modelo digital del terreno, un modelo digital de pendientes y la litología extraída del Mapa Geológico de España a escala 1:50 000. Para incluirlas en el análisis fue necesario convertir estos datos espaciales a hectáreas de ocupación para cada municipio empleando el sistema de información geográfica MiraMon (Pons, 2002). Esta operación requirió la reclasificación en intervalos de todas las variables continuas, excepto la litología al ser una variable categórica, la superposición con los límites municipales y, finalmente, la cuantificación de las hectáreas de ocupación para cada variable e intervalo. Una de las aportaciones del método, en comparación con otras investigaciones similares, es la inclusión en el modelo de más de 80 variables independientes.

Una vez convertidas, también, las variables dependientes (las CUS obtenidas en las clasificaciones automáticas) a hectáreas de ocupación e introducidas conjuntamente con las variables independientes en un paquete estadístico, a continuación se aplicó la regresión lineal multivariante. Este proceso se realizó para todos los subperiodos por separado, 1977, 1993, 1991 y 1997. Las hectáreas de ocupación para cada una de las variables biofísicas tenían el mismo valor en cada uno de los subperiodos al ser estáticas (medias anuales, etc.), mientras que los valores de las variables socioeconómicas variaban al ser dinámicas, de aquí la importancia de su inclusión.

La aplicación de la regresión lineal multivariante para cada uno de los subperiodos presentó unos $\mathrm{R}^{2}$ bastante elevados pero también diversos problemas. Uno de los más impor- 
tantes fue que se analizaron veintiún municipios y, por tanto, debido al corto número de casos los resultados podían estar muy sesgados a causa de la existencia de valores muy influyentes. Otro problema importante fue que algunas CUS sólo aparecían en determinados municipios, disminuyendo aún más el número de casos; el ejemplo más paradigmático fue el arroz que sólo aparecía en dos municipios. El último problema fue que la agregación en intervalos de las variables biofísicas comporta pérdida de información espacial y presenta serias dudas en el método de agregación.

\subsubsection{Regresión logística multivariante}

Para solventar los problemas descritos se aplicó la regresión logística multivariante (RLO) (Jovell, 1995), a escala de píxel, ya que ésta permite trabajar con variables dependientes dicotómicas, que es el caso de las CUS (por ejemplo, 1 = presencia de maíz, 0 = no presencia). En nuestro caso, el objetivo de la RLO fue predecir las probabilidades de presencia o no de las CUS a través de las variables independientes. Así, la diferencia respecto a la regresión lineal multivariante radica en que los valores resultantes indican probabilidades que según el valor umbral establecido (normalmente y en nuestro caso a partir de un valor de 0.5 o del $50 \%$ ) indicarán presencia o ausencia. Otra diferencia consiste en que el contraste del modelo se realiza a través de la curva ROC (Receiver Operating Characteristic). La probabilidad de la predicción se compara con los valores originales; si el ajuste es bueno los píxeles con presencia del respectivo uso agrario tendrán valores elevados de probabilidad mientras que los píxeles con ausencia respecto al uso agrario tendrán valores bajos de probabilidad. La curva ROC se obtiene de representar gráficamente los casos positivos (sensibilidad) y los negativos (especificidad) detectados correctamente. Valores cercanos a 1 indica que el modelo se ajusta perfectamente a los datos, mientras que valores de 0.5 indican un modelo aleatorio.

Al contrario del análisis a escala municipal, la inclusión de las variables biofísicas no comportó ningún problema debido a que inicialmente ya estaban a escala de píxel pero la inclusión de las variables socioeconómicas sí que generó problemas ya que éstas estaban agregadas a escala municipal en formato tabular. Para su conversión a formato digital se tuvo que transformar toda la información a formato vectorial y posteriormente rasterizar todas las variables a un píxel de medida compatible con las CUS y con las variables biofísicas, esto es a 60 m (1977 y 1993) y 30 m (1991 y 1997) respectivamente. El principal problema que comporta este proceso es que el resultado presenta una autocorrelación espacial máxima: todo los píxeles pertenecientes a un mismo municipio tienen el mismo valor. Por tanto, la combinación de variables socioeconómicas y biofísicas desde un SIG presenta serias limitaciones (Camacho et al., 2000). Para reducir la elevada autocorrelación espacial se seleccionó una muestra aleatoria del $10 \%$ de los casos con presencia (para cada CUS) y del $10 \%$ con ausencia con lo cual se garantizaba, también, una probabilidad inicial del $50 \%$.

\subsubsection{Fuerzas inductoras de los cambios}

Los resultados de la RLI y de la RLO en el subperiodo 1977-1993 mostraron que las variables más explicativas en relación con los cultivos herbáceos (con la excepción de los cereales de invierno) y a los frutales eran los materiales aluviales, y la baja altitud y pendiente (RLO(-) y RLI (de 0 a $3^{\circ}$ ) (tabla 2). También destaca el plan de regadío del río Muga como factor explicativo del maíz. Para los cultivos permanentes (olivos y vides) los materiales más antiguos eran los factores más explicativos, junto a la temperatura máxima anual 


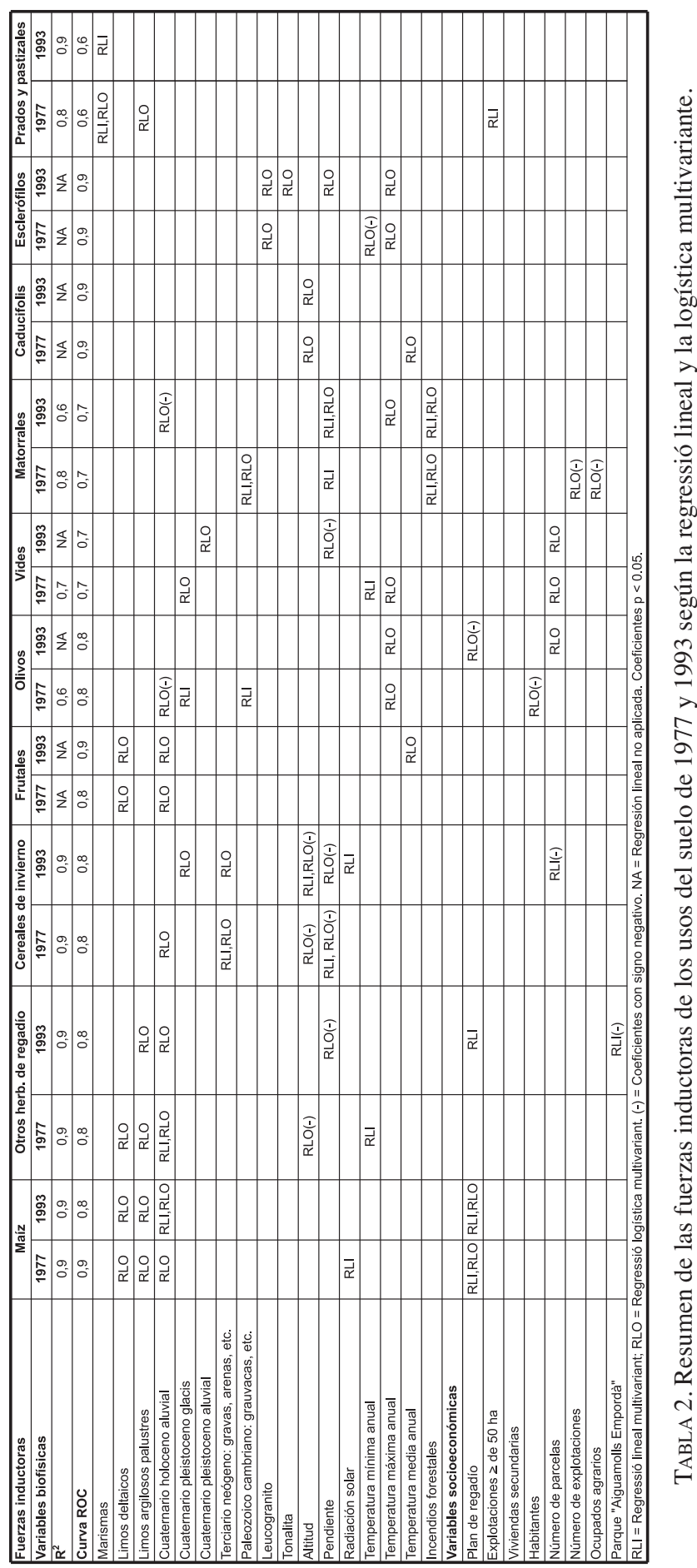


y a la atomización parcelaria. Así, según el Ministerio de Agricultura (1976) la superficie media de las parcelas de vid era inferior a 1 hectárea.

La altitud era la variable más explicativa en el caso de los caducifolios, mientras que el leucogranito, la tonalita y la temperatura máxima anual lo eran en el caso de los esclerófilos. El incremento de los matorrales se debió a los incendios forestales y al abandono agrícola de las zonas más marginales, de aquí la importancia del pendiente. Finalmente, el factor más determinante para los prados y pastizales era las marismas.

Entre 1991 y 1997, los resultados en relación a los cultivos herbáceos y a los frutales fueron similares al subperiodo 1977-1993 (tabla 3): importancia significativa de los materiales más recientes, coeficientes negativos con la altitud y pendiente y para el caso del maíz el plan de regadío y un nuevo factor que era los subsidios de la Política Agraria Común (PAC), bastantes elevados debido al déficit europeo en grasas vegetales en ese periodo. En relación al girasol la PAC también aparecía como muy explicativa junto a los materiales recientes. Para el caso del arroz los factores más importantes correspondían a los materiales cuaternarios donde la disponibilidad de agua es mayor. Destaca, también, la menor pérdida de olivos y vides que se debió a una mayor demanda de aceite de oliva y a la finalización del proceso de transformación vitícola iniciado el 1987. Es de destacar que en este subperiodo la menor presencia de incendios forestales evitó un mayor crecimiento de los matorrales, mientras que el factor más importante en el estancamiento de la pérdida de prados y pastizales fue la creación en 1986 del Parque de los Aiguamolls (marismas) del Ampurdán, ya que una de las prioridades de los gestores era y es su mantenimiento.

\subsection{Consecuencias paisajísticas de los cambios}

El último apartado de la metodología se basa en el análisis de las consecuencias paisajísticas de los cambios en las CUS anteriormente descritos. Desde la Ecología del Paisaje, se considera que un paisaje está formado por un conjunto de unidades distribuidas en el espacio y que están relacionadas por una serie de flujos (de energía, etc.). Las propiedades físicas como la medida, la forma y la distribución espacial de las diversas unidades son el resultado de los procesos funcionales que ocurren a escala del paisaje (Pino y Rodà, 1999; Holt-Jensen, 1999). Las unidades del paisaje son las manchas (patches en inglés), definidas como las superficies con características homogéneas y diferentes de las de su alrededor, cuyos principales atributos topológicos son la medida, la forma, el número y su disposición. Según Turner (1989), el mosaico paisajístico resultante es fruto de las acciones humanas y naturales, de las interacciones entre las fuerzas socioeconómicas y biofísicas.

El objetivo de este apartado ha consistido en la cuantificación de diversos índices para cada uno de los mapas de CUS y su posterior comparación siguiendo los subperiodos de 1977 a 1993 y de 1991 a 1997. Para ello se han cuantificado los siguientes índices (McGarigal y Marks, 1994): el número de manchas, el área media de las manchas en hectáreas, el índice de la mancha mayor, el coeficiente de variación de la medida de las manchas y el índice de la forma paisajística (cuanto más pequeño la CUS presenta una forma más regular, más cuadrada).

Las principales dinámicas paisajísticas en la zona llana fueron la tendencia a la homogeneización del maíz (especialmente entre 1977 y 1993), del arroz y del girasol (1991 y 1997), mientras que en los frutales se produjo exclusivamente en el periodo 1977 y 1993 (tabla 4). Las CUS que presentaban una tendencia a la fragmentación eran los otros herbáceos de regadío, los cereales de invierno, las vides (especialmente entre 1977 y 1993), los 


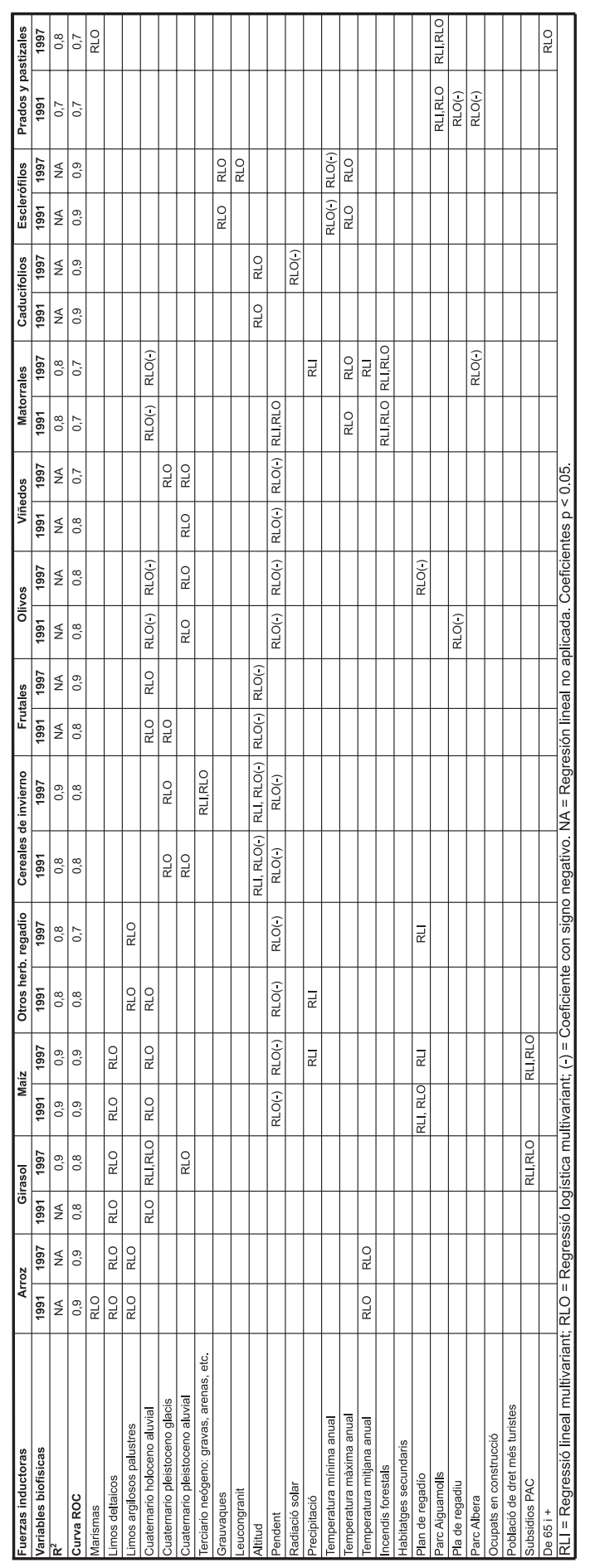

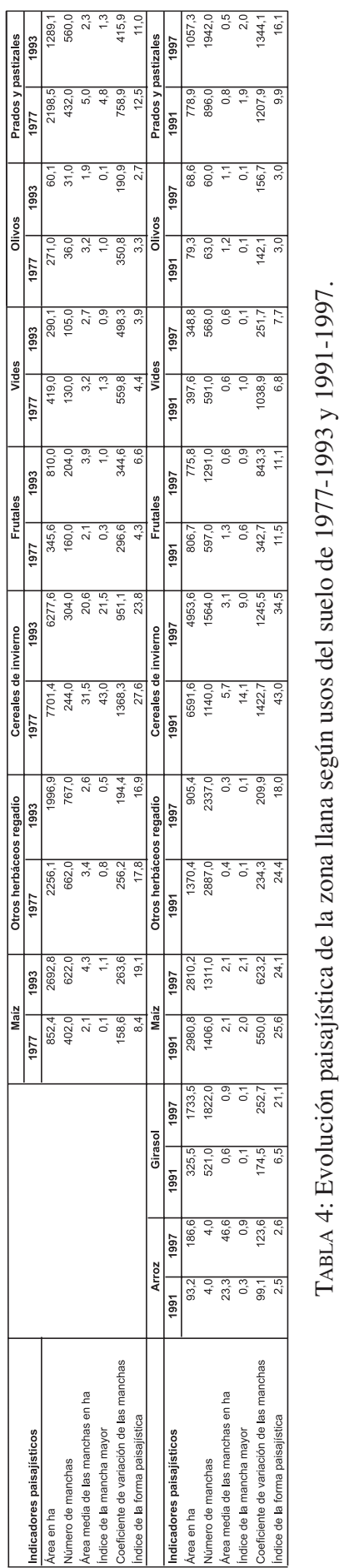


olivos (especialmente entre 1977 y 1993) y los prados y pastizales (especialmente entre 1977 y 1993), todos ellas en clara regresión.

En la zona de transición destacaba la homogeneización del maíz, de otros herbáceos de regadío y de los cereales de invierno y la clara fragmentación de vides, olivos y prados y pastizales, especialmente en el periodo 1977 y 1993, debido a su abandono (tabla 5). En el periodo 1991-1997, estos procesos se detienen, mientras que los esclerófilos presentaban un incremento de la homogeneización gracias a la aforestación natural de los incendios forestales.

Finalmente, en la zona de montaña, las principales tendencias fueron la fragmentación, también, de los cereales de invierno, vides, olivos y prados y pastizales, especialmente entre 1977 y 1993, y la homogeneización de la superficie forestal, consecuentemente (tabla 6).

\section{Conclusiones}

La combinación de la metodología descrita se configura como una herramienta de gran potencial para el análisis territorial y paisajístico. El análisis histórico nos permite comprender que el proceso de transformación debido a la acción humana a lo largo de los siglos ha sido y es permanente. Por otro lado, la teledetección y los SIG nos permiten analizar los cambios recientes con una elevada exactitud y fiabilidad. Cabe destacar que en el proceso de obtención de los cambios es imprescindible usar CUS obtenidas de fuentes idénticas para evitar resultados ficticios. En nuestro caso ha comportado la imposibilidad de analizar los cambios de 1977 a 1997 con sólo dos mapas.

Por su parte, el análisis estadístico aporta resultados cuantitativos de gran interés que ayudan a reforzar o contrastar las hipótesis cualitativas de partida. El análisis estadístico a través de la regresión lineal y de la logística multivariante ha aportado resultados muy explicativos a pesar de las problemáticas apuntadas. En el caso de aplicar la regresión lineal multivariante es de gran importancia el número de casos para evitar coeficientes sesgados, mientras que el mayor problema de la regresión logística es la elevada autocorrelación espacial de las variables socioeconómicas. A pesar de ello, los resultados muestran unos coeficientes de determinación $\left(\mathrm{R}^{2}\right)$ y unos valores en la curva ROC significativamente elevados, con la excepción de los prados y pastizales de 1977 y 1993. Finalmente, los índices paisajísticos han permitido analizar la evolución de las CUS, estableciendo las principales tendencias en cuanto a fragmentación o homogeneización.

De los resultados obtenidos, se desprende que el paisaje altoampurdanés analizado se encontraba a finales del s. XX en un proceso de transformación paisajística de notables repercusiones. Del análisis realizado se desprende que en la zona llana permanece un menor número de explotaciones agrarias, pero más extensas, con unos cultivos mayoritariamente subsidiados por la PAC y más homogéneos, menos fragmentados territorialmente. Este hecho se constata claramente en el caso de los cereales de invierno cada vez en mayor regresión, en detrimento del maíz de regadío, conjuntamente con un incremento del sector turístico que conlleva un aumento de la demanda de suelo urbanizable.

La homogeneización de las CUS se ha detectado claramente en la zona de montaña donde las amplias masas forestales incrementan debido al abandono de vides y olivos, con el consiguiente riesgo de incendios forestales más destructivos. En este sentido, el mantenimiento de los cultivos restantes sería prioritario ya que se encuentran situados en zonas con una elevada radiación solar y, por tanto, con un mayor riesgo de incendios. Este hecho queda patente en la zona de transición donde los matorrales es la CUS mayoritaria. 


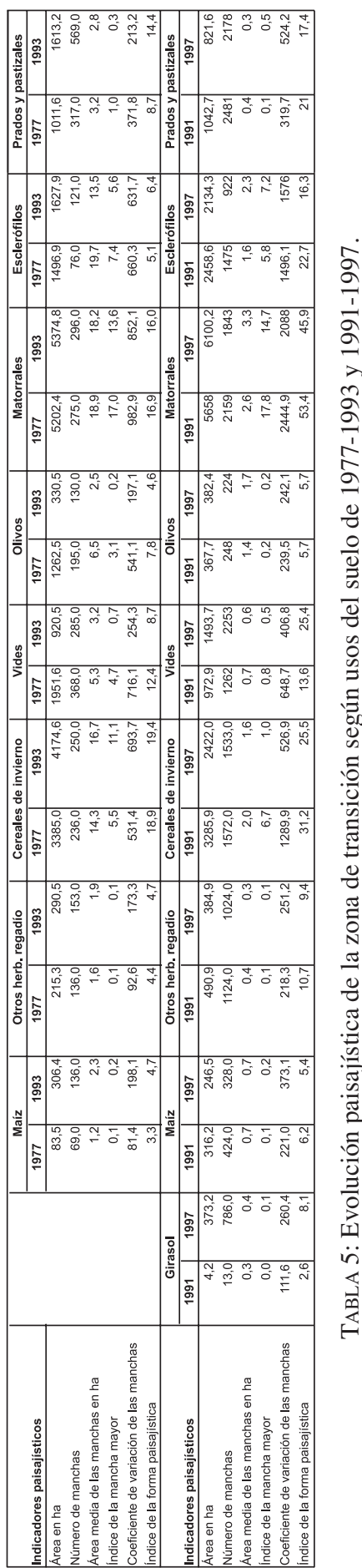

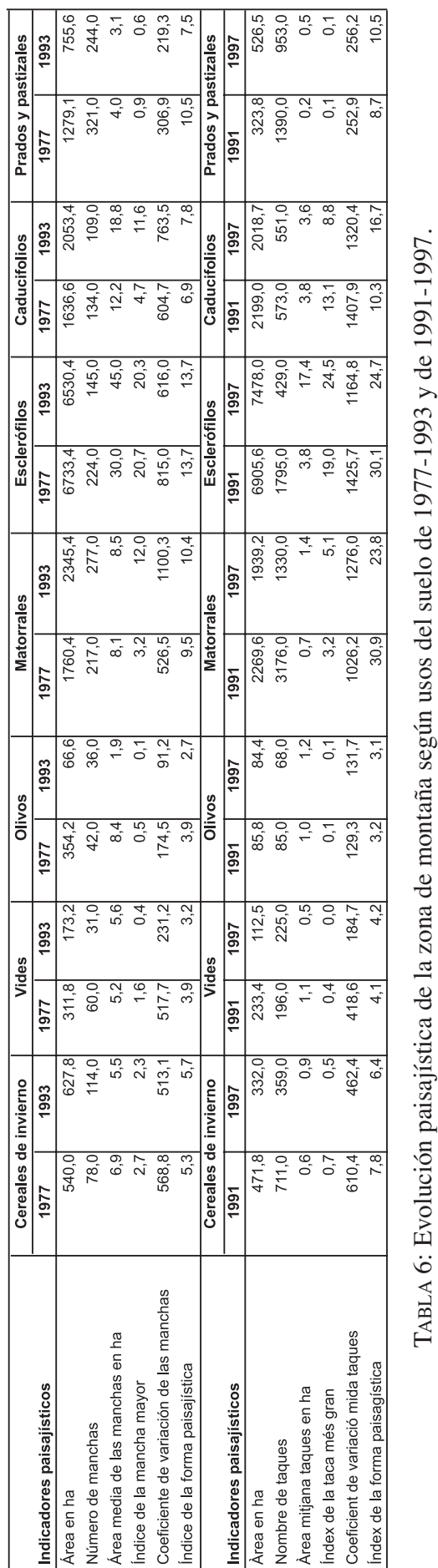

Investigaciones Geográficas, nº 36 (2005) 


\section{BIBLIOGRAFÍA}

ARMENGOL, D. (1978): Les transformacions de l'agricultura: alguns aspectes de la revolució agronòmica a l'Alt Empordà. En Alberch, R. et al.: Girona al s. XIX. Gòthia Edit, Girona, pp. 65-94.

CAMACHO, M.; PAEGELOW, M.; MENOR, J. (2000): «Límites y aportaciones de los SIG para trazar la dinámica espaciotemporal del paisaje en áreas montañosas mediterráneas», en Actas del IX Congreso del Grupo de Métodos Cuantitativos, Sistemas de Información Geográfica y Teledetección, Departamento de Geografía de la Universidad de Alcalá, pp. 381-401.

COMPTE, A. (1963-64): «El Alto Ampurdán», en Pirineos, nº 66-67, pp. 5-283.

CHUVIECO, E. (2002): Teledetección ambiental. Ariel. Barcelona, 586 pp.

DÍAZ, J. (1986). Geografía y agricultura. Cuadernos de Estudio, serie G, 4. Cincel. Madrid, $128 \mathrm{pp}$.

HOLT-JENSEN, A. (1999): Geography. History and concepts. Sage Publications, London, $248 \mathrm{pp}$.

INSTITUTO NACIONAL DE ESTADÍSTICA (INE) (1964). Primer Censo Agrario de España, octubre de 1962. Gerona. Madrid, 85 pp.

JOVELL, A.J. (1995): Análisis de regresión logística. Cuadernos metodológicos, 15. Centro de Investigaciones Sociológicas, Madrid, $118 \mathrm{pp}$.

KONING, G.H.J.; VELDKAMP, A.; FRESCO, L.O. (1998): «Land use in Ecuador: a statistical analysis at different aggregation levels», en Agriculture, Ecosystems and Environment, $\mathrm{n}^{\circ}$ 70, pp. 231-247.

LIVERMAN, D.; MORAN, E.F.; RINDFUSS, R.R.; STERN, P.C. (Ed) (1998): People and pixels. National Academy Press, Washington, $244 \mathrm{pp}$.

LOWE, J.J.; WALKER, M.J.C. (1997): Reconstructing quaternary environments. Longman, England, 446 pp.

MCGARIGAL, K.; MARKS, B. (1994). Fragstats: spatial pattern analysis program for quantifying landscape structure. Disponible en: ftp: //ftp.fsl.orst.edu/pub/fragstats.2.0/frag.zip

MINISTERIO DE AGRICULTURA (1976): Catastro vitícola y vinícola. Denominación de Origen Ampurdán-Costa Brava. Servicio de Publicaciones Agrarias, Madrid, 101 pp.

NINYEROLA, M.; PONS, X.; ROURE, J.M. (1999): «A methodological approach of climatological modelling of temperature and precipitation trough GIS». International Journal of Climatology, ${ }^{\circ}$ 20, pp. 1823-1841.

PALÀ, V.; PONS, X. (1995): «Incorporation of relief in polynomial-based geometric corrections». Photogrammetric Engineering and Remote Sensing, n 61, pp. 935-944.

PINO, J.; RODÀ, F. (1999): «L'ecologia del paisatge: un nou marc de treball per a la ciència de la conservació». Butlletí de la Institució Catalana d'Història Natural, nº 67, pp. 5-20.

PONS, X. (2000): MiraMon. Geographic Information System and Remote Sensing software. Centre de Recerca Ecològica i Aplicacions Forestals, CREAF. Bellaterra. http://www.creaf.uab.es/miramon

PONS, X.; SOLÉ-SUGRAÑES, L. (1994): «A simple radiometric correction model to improve automatic mapping of vegetation from multispectral satellite data». Remote Sensing of Environment, 48, p. 191-204.

RIBAS, A.; SAURÍ, D. (Ed) (2002). Canvis socioambientals a l'Alt Empordà (1950-2000). Natura $i$ història en l'evolució recent del paisatge altempordanès. Servei de Publicacions de la Universitat de Girona, Girona, 264 pp. 
SERRA, P.; PONS, X.; SAURÍ, D. (2003a): «Post-classification change detection with data from different sensors: some accuracy considerations». International Journal of Remote Sensing, $\mathrm{n}^{\circ}$ 24, pp. 3311-3340.

SERRA, P.; PONS, X.; SAURÍ, D. (2003b): «Protocolo para la identificación de cambios a través de diferentes sensors». Revista de Teledetección, $\mathrm{n}^{\circ}$ 16, pp. 17-24.

TURNER, M. (1989): «Landscape ecology: the effect of pattern on process». Annual Review of Ecology and Systematics, $\mathrm{n}^{\circ} 20$, pp. 171-197.

WALKER, M. (1977): Agricultural location. Basil Blackwell, Oxford, 80 pp.

WOOD, C.H.; SKOLE, D. (1998): Linking satellite, census and survey data to study deforestation in the Brazilian Amazon. En: Liverman, D.; Moran, E.F.; Rindfuss, R.R. y Stern, P.C. (Ed). People and Pixels. National Academy Press, Washington, pp. 70-93. 